Available online on 15.11.2016 at http://jddtonline.info
(C) 2016, publisher and licensee JDDT, This is an Open Access article which permits unrestricted
noncommercial use, provided the original work is properly cited

Review Article

\title{
ALZHEIMER'S DISEASE: DELIVERY OF DRUGS THROUGH INTRANASAL ROUTE
}

\author{
Sana Farooqui* ${ }^{1}$, Mohammad Zahid ${ }^{1}$, Shahla Parveen ${ }^{1}$, Zeeshan Ahmad $^{2}$, Prashant K Singh ${ }^{1}$, Zeba Parveen ${ }^{3}$ \\ ${ }^{1}$ Department of Pharmacology, Faculty of Pharmacy, Integral University, Dasauli, Kursi Road, Lucknow, India-226026 \\ ${ }^{2}$ Department of Pharmaceutics, Faculty of Pharmacy, Integral University, Dasauli, Kursi Road, Lucknow, India-226026 \\ ${ }^{3}$ Department of Bioscience, Faculty of Science, Integral University, Dasauli, Kursi Road, Lucknow, India-226026
}

\begin{abstract}
Alzheimer's disease (AD) is a progressive neurodegenerative disorder characterized by severe cognitive impairments. A major histopathological hallmark of AD is the presence of amyloid deposits in the parenchyma of the amygdala, hippocampus, and neocortex. $\beta$-amyloid is a small piece of a larger protein called "amyloid precursor protein" (APP). The main component of amyloid is the $\beta$-Amyloid protein $(\mathrm{A} \beta)$, a 39.43 amino acid peptide composed of a portion of the transmembrane domain and the extracellular domain of the APP. A $\beta$ deposition leads to synaptic degeneration and interacts with different types of central nervous system receptors; hence, it disrupts neuronal homeostasis. Moreover, A $\beta$ deposition along the cerebral vessels alters their tonicity and triggers some of the cerebrovascular deficits. Furthermore, its accumulation disrupts intracellular $\mathrm{Ca} 2+$ homeostasis which ultimately reduces neuronal $\mathrm{Ca} 2+$ buffering capacity and increases excitotoxicity outcomes. The emerging approach is to bypass the BBB by intranasal delivery, which provides a practical, noninvasive, rapid and simple method to deliver the therapeutic agents to the CNS. This method works the unique connection between the nose and the brain that has evolved to sense odors and other chemical stimuli. On the basis of clinical trials (Phase I and II) it is reported that the intranasal route is feasible for the transport of the drug to the CNS. Intranasal delivery does not require any modification of the therapeutic agents and does not require that drugs be coupled with any carrier like in case of drug delivery across the BBB. A wide variety of therapeutic agents, including both small molecules and macromolecules can be successfully delivered, including to the CNS, using the intranasal method.
\end{abstract}

Key Words: Alzheimer's disease, $\beta$-amyloid, cerebrovascular deficits, excitotoxicity

*Corresponding author

Sana Farooqui, Research Scholar, Faculty of Pharmacy, Integral University. Dasauli, Kursi Road, Lucknow, 226026

E-Mail: farooquisana007@gmail.com, Mob. No. +91-8182849987

Article Info

Received 31 Oct 2016; Review Completed 11 Nov 2016; Accepted 11 Nov 2016, Available online 15 Nov 2016

URI: http://jddtonline.info/index.php/jddt/article/view/1348

Cite this article as: Farooqui S, Zahid M, Parveen S, Ahmad Z, Singh PK, Parveen Z, Alzheimer's disease: delivery of drugs through intranasal route, Journal of Drug Delivery \& Therapeutics. 2016; 6(6):60-69 DOI: http://dx.doi.org/10.22270/jddt.v6i6.1348

\section{INTRODUCTION}

The blood-brain barrier (BBB) is located at the level of the cerebral microvasculature and is critical for maintain central nervous system (CNS) homeostasis. Although the $\mathrm{BBB}$ restricts the entry of potentially neurotoxic substances in the brain, it also presents a major obstacle to the delivery of therapeutics into the CNS for disease treatment. The BBB exhibits a small rate of pinocytosis and possesses tight junctions (TJ) which form a seal between opposing endothelial membranes ${ }^{1}$. The presence of $\mathrm{TJ}$ at the $\mathrm{BBB}$ creates a high transendothelial electrical resistance of 1500-2000 $\Omega \cdot \mathrm{cm}^{2}$ compared to $3-30 \Omega \cdot \mathrm{cm}^{2}$ across most peripheral microvessels ${ }^{\mathbf{2 , 3}}$. This high resistance is associated with very low permeability, i.e. the BBB greatly restricts paracellular diffusion of solutes from the blood into the brain. Typically, only minute, lipophilic molecules appreciably cross the normal, healthy BBB via transcellular passive diffusion, although some limited transport of certain peptides and peptide analogs has been reported ${ }^{4}$. Essential nutrients such as glucose or iron gain entry into the CNS through specific 
transporters such as the glucose transporter 1 or receptors such as the transferrin receptor ${ }^{\mathbf{5 , 6}}$. Receptors and transporters for gastrointestinal hormones involved in regulating metabolism are expressed at the BBB in order to convey information between the CNS and periphery ${ }^{7}$. In addition to its low paracellular permeability and low rate of pinocytosis, the BBB also expresses a high number of drug transporters (e.g. Pglycoprotein) which further restrict brain entry of many endogenous and exogenous substances that would otherwise be predicted to cross the BBB based on molecular weight (MW) and lipophilicity considerations 8,9

Although there are many examples of small MW drugs which cross the $\mathrm{BBB}$, nearly all large MW substances are severely restricted from crossing the BBB under normal conditions; indeed, the only examples of large MW drugs approved for clinical use in treating a neurological illness are those that act via peripheral mechanisms. Many large MW substances have shown substantial promise in treating aspects of CNS diseases based on studies utilizing in vitro systems and animal models. However, it will likely be necessary to implement drug delivery strategies that overcome the formidable obstacles presented by the various barriers of the CNS (the BBB and blood-cerebrospinal fluid (CSF) barriers) for these studies to ultimately be translated to the clinic ${ }^{\mathbf{1 0}}$. Intraparenchymal, intracerebroventricular, and intrathecal injections/infusions are capable of delivering therapeutics directly to the CNS, but these routes of administration are invasive and likely not practical for drugs which need to be given chronically. The intranasal (IN) route of administration provides a non-invasive method of bypassing the BBB to potentially deliver biologics such as peptides, proteins, oligonucleotides, viral vectors, and even stem cells to the CNS.

\section{OVERVIEW OF ALZHEIMER'S DISEASE}

Alzheimer's disease (AD) is a degenerative brain disease and the most common cause of dementia. Dementia is characterized by a decline in memory, language, problem solving and other cognitive skills that affects a person's ability to perform everyday activities. This decline occurs because nerve cells (neurons) in parts of the brain involved in cognitive function have been damaged or destroyed. In Alzheimer's disease, the damage and destruction of neurons eventually affects other parts of the brain, including those that enable a person to carry out basic bodily functions such as walking and swallowing. People in the final stages of the disease are bed-bound and require around-the-clock care. Alzheimer's disease is ultimately fatal.

\section{Dementia}

Physicians may refer to the Diagnostic and Statistical Manual of Mental Disorders (DSM) to guide them in determining if an individual has dementia, and, if so, what may be the cause. Based on the latest DSM criteria 11, dementia is classified as a major neurocognitive disorder because it interferes with both cognitive function and performing everyday activities. Cognitive function refers to memory, speech, language, judgment, reasoning, planning and other thinking abilities. Examples of everyday activities are making a meal, paying bills, and traveling to a store to make a purchase.

When an individual has symptoms of dementia, such as memory or language problems, a physician will conduct tests to identify the cause. Studies indicate that many people with dementia, especially those in the older age groups, have brain abnormalities associated with more than one cause of dementia ${ }^{\mathbf{1 2 , 1 3}}$. This condition is called mixed dementia.

In some cases, individuals with symptoms of dementia do not have dementia, but instead have a condition whose symptoms mimic those of dementia. Common causes of dementia like symptoms are depression, delirium, side effects from medications, thyroid problems, certain vitamin deficiencies and excessive use of alcohol. Unlike dementia, these conditions often may be reversed with treatment. One meta-analysis, a method of analysis in which results of multiple studies are examined, reported that 9 percent of people with dementia-like symptoms did not in fact have dementia, but had other conditions that were potentially reversible 14.

\section{Alzheimer's disease}

Alzheimer's disease was first identified more than 100 years ago, but 70 years passed before it was recognized as the most common cause of dementia, as well as a major cause of death ${ }^{\mathbf{1 5}}$. Not until then did Alzheimer's disease become a significant area of research. Although the research that followed has revealed a great deal about Alzheimer's, much is yet to be discovered about the precise biological changes that cause Alzheimer's, why it progresses more quickly in some than in others, and how the disease can be prevented, slowed or stopped.

Researchers believe that early detection of Alzheimer's will be key to preventing, slowing and stopping the disease. The last 10 years have seen tremendous growth in research on early detection. This research spurred the 2011 publication of new diagnostic criteria and guidelines for Alzheimer's disease 16,17. According to the criteria, the brain changes of Alzheimer's begin before symptoms such as memory loss appear, whereas earlier criteria require memory loss and a decline in thinking abilities for an Alzheimer's diagnosis to be made. Because scientific evaluation of some components of the new criteria is ongoing, "Alzheimer's disease" in this report refers to the disease as defined by the earlier criteria ${ }^{18}$.

\section{Symptoms}

The most common initial symptom is a gradually worsening ability to remember new information. This occurs because the first neurons to be damaged and destroyed are usually in brain regions involved in forming new memories. As neurons in other parts of the brain are damaged and destroyed, individuals experience other difficulties. The following are common symptoms of Alzheimer's: 
$>$ Memory loss that disrupts daily life.

$>$ Challenges in planning or solving problems.

> Difficulty completing familiar tasks at home, at work or at leisure.

$>$ Confusion with time or place.

$>$ Trouble understanding visual images and spatial relationships.

$>$ New problems with words when speaking or writing.

> Misplacing things and losing the ability to retrace steps.

$>$ Decreased or poor judgment.

$>$ Withdrawal from work or social activities.

$>$ Changes in mood and personality, including apathy and depression.

$>$ Increased anxiety, agitation and sleep disturbances.

\section{PATHOPHYSIOLOGY OF ALZHEIMER'S DISEASE}

With pathophysiology of $\mathrm{AD}$, debate goes back to the Alzheimer's time 1907 when he observed the neuropathological features of the disease i.e. amyloidal plaques and hyperpho-sphorylated NFTs. Several hypotheses have been put forward on the basis of the various causative factors in order to explain this multifactorial disorder ${ }^{19}$ such as the cholinergic hypothesis, A $\beta$ hypothesis, tau hypothesis and inflammation hypothesis ${ }^{\mathbf{2 0}}$. Recently it has been shown that the most commonly used $A \beta$ hypotheses, prevailing for the last two decades, does not account for the complex pathophysiology of this incapacitating disease 21. Recent studies have also highlighted the role of $A \beta$ oligomers in synaptic impairment, suggesting that these are primarily the only one among several other signals

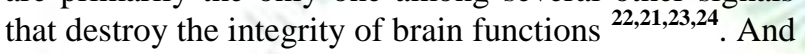
formations of amyloid plaques that develop in the later age appear to be rather late event ${ }^{23}$.

According to the amyloid cascade hypothesis, the APP is normally cleaved by $\alpha$-secretase and aberrantly processed by $\beta$ - and $\gamma$-secretases (Fig. 1) resulting in an imbalance between production and clearance of $A \beta$ peptide ${ }^{25}$. As a consequence, A $\beta$ peptides spontaneously aggregate into soluble oligomers and coalesce to form fibrils insoluble beta-sheet conformation and are eventually deposited in diffuse senile plaques ${ }^{21}$. Some recent studies have shown that A $\beta 42$ oligomers are produced by cooperative activities of both neurons and its associated astrocytes ${ }^{\mathbf{2 3}}$. It has been observed that $\mathrm{A} \beta 42$ oligomers induce oxidative damage, promote tau hyperphosphorylation, results in toxic effects on synapses and mitochondria ${ }^{20,19}$. But the role of $\mathrm{A} \beta 42$ senile plaques cannot be ignored as $A \beta 42$ plaques that are supposed to be appearing during late stage attract microglia ${ }^{26}$. Microglial activation results in production and release of pro-inflammatory cytokines, including IL-1 $\beta, \mathrm{TNF}-\alpha$, and IFN- $\gamma$. In turn, these cytokines stimulate the nearby astrocyte-neuron to produce further amounts of $\mathrm{A} \beta 42$ oligomers, thus activating more $A \beta 42$ production and dispersal ${ }^{23}$. Oligodendroglia (OLGs) is also associated with neurons-astrocyte complex; $\mathrm{A} \beta$ oligomers also results in its destruction ${ }^{27}$. A $\beta$ oligomers aggregates are considered to be responsible for the neuronal and vascular degeneration in $\mathrm{AD}$ brains ${ }^{28}$. It results in oxidative stress, a situation to which OLGs are particularly susceptible because their reduced glutathione (GSH) content is low and they have a high concentration of iron, thus presenting an impaired ability to scavenge oxygen radicals ${ }^{28}$. It has also been reported that $\mathrm{A} \beta 42$ oligomers possesses an increased capability for damaging cholesterol rich membranes, such as those found in OLGs and myelin ${ }^{\mathbf{2 8 , 3 0}}$.

Previous studies about the receptors pharmacology of $\mathrm{A} \beta$ have shown that $\mathrm{A} \beta 42$ monomers activate the neuroprotective signaling of insulin-like growth factor-1 receptor (IGF-1R), while $A \beta 42$ oligomers target a host of neurons' and astrocytes' membrane receptors, such as the scavenger receptor for advanced glycation end products (RAGE), Frizzled receptor, insulin receptor, NMDA-glutamate receptor, p75 neurotrophin receptor (p75NTR), $\alpha 7$ nicotinic ACh receptor $(\alpha 7 \mathrm{nAChR})$, ApoE receptors, formyl peptide receptor-like 1 (FPRL1/2), cellular prion protein (PrPc) acting as an $\mathrm{A} \beta$ oligomer receptor, and the calcium-sensing receptor (CaSR) ${ }^{31,32}$. Removal of $A \beta$ oligomers from the brain occurs by several pathways including proteolytic degradation by the proteases neprilysin and insulin degrading enzyme (IDE), uptake by astrocytes and microglia, passive flow into the cerebrospinal fluid and sequestration into the vascular compartment by soluble form of the low-density lipoprotein receptor related protein 1 (LRP1) ${ }^{33,34}$. The effect of NO on IDEmediated degradation of $A \beta$ has been studied and it has been shown that increased NO levels, which have been observed in $\mathrm{AD}$, can decrease IDE enzymatic function, potentially resulting in increase in $\mathrm{Ab}$ oligomers deposition in the brain and development of $\mathrm{AD}^{\mathbf{3 5}}$.

Recently it has been shown that there is a "contagion", like diffusion of A $\beta 42$ oligomers and hyperphosphorylated tau oligomers via exocytosis (synapses) or exosomes to closely associated target cells (astrocytes and oligodendrocytes), which in turn become producer cells of $\mathrm{A} \beta$ and tau oligomers ${ }^{36}$. Experimental evidence have shown that intracerebral (i.c.) administration of minute amounts of brain extract containing misfolded $\mathrm{A} \beta$ from patients with $\mathrm{AD}$ or from A $\beta$-APP transgenic ( $\mathrm{tg}$ ) mice induces cerebral bamyloidosis and related pathologies in APP tg mice in a time and concentration-dependent manner ${ }^{37}$.

The important consequence of the astrocyte-neuron interconnections is the astrocytes abilities to promote or reduce neurotransmitters release into the synapses they envelop with the $\mathrm{Ca}^{2+}$ they respectively let out or take up during their $\mathrm{Ca}^{2+}$ waves ${ }^{27}$. When neurons $\mathrm{A} \beta 42$ production exceeds the safe limit, toxic $A \beta 42$ oligomers start spilling out of the neurons and onto their enveloping astrocytes both cell types being empowered with A $\beta 42$ oligomer-binding receptors besides accumulating or dispersing in the extracellular surrounding ${ }^{23}$. Because of the intimate physical and functional interdigitations in the neurons client group, the A $\beta 42$ oligomers releases by the neuron can directly bind to the $\alpha-7$ nAChRs of its partner astrocytes. The 
signals from these receptors induce the astrocytes to exocytose the glutamate they have been taking up from the neuronal synapses ${ }^{38}$. The discharged glutamate activates the extrasynaptic NMDARs of the astrocytes' partner neurons ${ }^{37,35}$. The resulting signals trigger $\mathrm{Ca}^{2+}$ surges evoking a cascade of events, including dysfunctional mitochondria pumping out ROS, which inflict an oxidative damage, caspase 3 activation, tau hyperphosphorylation, excess production of NO, ROS and VEG-F thereby destroying dendritic spines and neuronal synapses and severing communications within the astrocyte's neurons and beyond ${ }^{32}$. Armato and others have shown that CaSRs (present on the cell membranes of astrocytes and neurons on which A $\beta 42$ oligomers binds) selective allosteric antagonist (calcilytic) NPS 2143 specifically stops the excess release of endogenous $A \beta 42$ from the $A \beta 25-35$-exposed human astrocytes and neurons ${ }^{32,38}$.

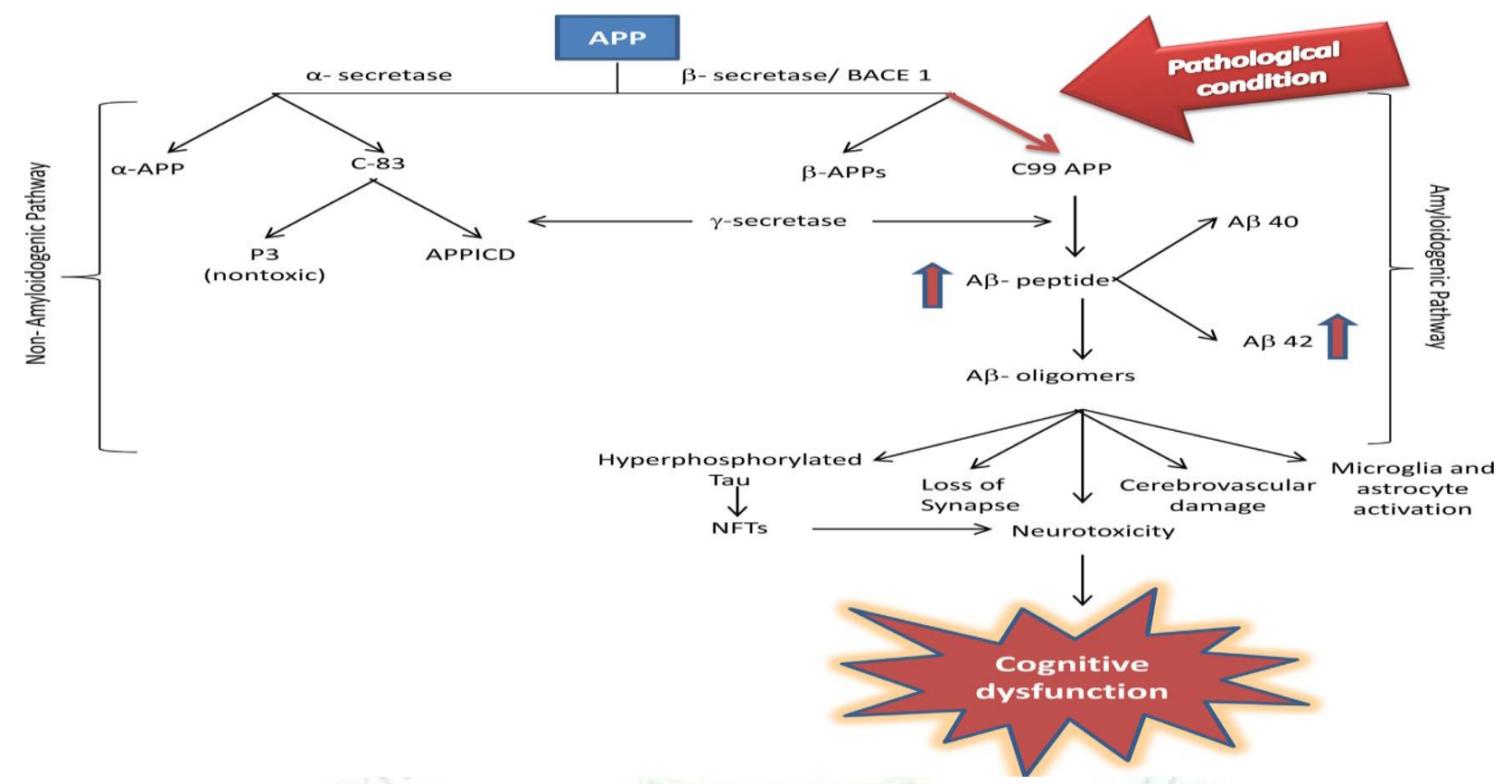

Figure 1: Diagrammatic presentation of APP processing pathways ${ }^{39}$.

\section{INTRANASAL DELIVERY}

Intranasal nose to brain (N2B) delivery to the upper third of the nasal cavity bypasses the blood-brain barrier to rapidly target therapeutics to the CNS along the olfactory and trigeminal neural pathways (for excellent summary see $\left.{ }^{40}\right)$. The N2B route of administration provides a non- to minimal-invasive method of bypassing the BBB.

\section{Anatomy and histology of the nasal cavity}

The nasal cavity is divided longitudinally by the nasal septum and extends from the nostrils to the nasopharynx (roughly 12-14 cm), but has an impressively large mucosa surface area (about $160 \mathrm{~cm} 2)^{\mathbf{4 0 , 4 1}}$. The frontal and lateral views are shown in Figure 2. Three turbinates (also called conchae) are the cause for the large surface area and their biological function is to humidify, warm and filter the inspired air. Nasal secretions and inhaled particles are transported to the nasopharynx via mucociliar clearance, where they are swallowed or expectorated. Importantly, the nasal mucosa provides very important immune function since countless inhaled pathogens are filtered here and transported to the nasopharynx-associated lymphoid tissue ${ }^{42}$. Therefore, intranasal vaccinations like
FluMist ${ }^{\circledR}$ replace more and more injection-associated vaccinations

The nasal mucosa consists of four different epithelia: respiratory, olfactory, squamous and transitional epithelium ${ }^{43}$. The squamous epithelium covers the nasal vestibule from the nostrils to the anterior part of the turbinates and harbours hairs and glands. The transitional epithelium is located at the transitions between the other three types of epithelium and appears not to have a relevant role in intranasal delivery.

The nasal respiratory epithelium is a pseudostratified columnar secretory epithelium that is formed by ciliated cells, goblet cells, intermediate cells and basal cells. The tissue shares high similarity to therespiratory epithelium of the lung and covers up to $90 \%$ of the nasal cavity in humans and roughly $50 \%$ in rodents ${ }^{\mathbf{4 0}}$. Through close contact with inspired air, it warms and humidifies the air and air-borne particles and pathogens are removed. Different serous glands produce the nasal mucus and nasal secretion that are propelled from the ciliated cells to the nasopharynx. The mucus is well characterized and creates a mild acidic and antibacterial milieu with a $\mathrm{pH}$ of $5.5^{-6.5}{ }^{\mathbf{4 1}}$. The nasal respiratory epithelium is innervated by the trigeminal nerve, the fifth of the cranial nerves. Numerous intraepithelial trigeminal fibres are located near the basal region of the 
epithelium; some of them extending outward to nearly reach the epithelial surface stopping at the line of tight junctions about $1 \mu \mathrm{m}$ from the surface ${ }^{44}$. The largely branched trigeminal nerve projects mainly but not exclusively to the brainstem and is highly implicated into N2B transport ${ }^{\mathbf{4 4 , 4 5}}$. The respiratory epithelium has a large surface and is highly perfused; hence well suitable for the systemic absorption of drugs ${ }^{\mathbf{4 6}}$.
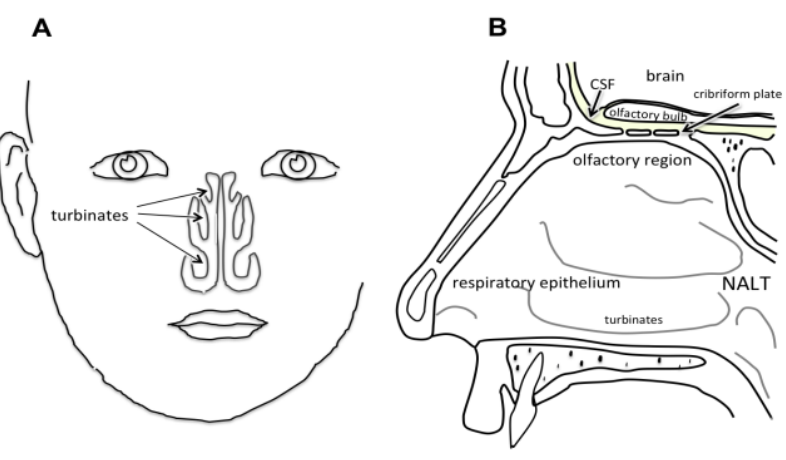

Figure 2: The anatomy of the human nasal cavity. The olfactory region permits the transport of APIs to the CSF and the olfactory bulb. (A) frontal view with inferior, middle and superior turbinate. (B) lateral view with cribriform plate, olfactory bulb and CSF in close vicinity to the olfactory region. The nasopharynx-associated lymphatic tissue (NALT) has immunological functions and is located in lower part of the nasal cavity close to the nasopharyn $\mathrm{x}^{47}$.

The olfactory cleft at the roof of the nasal cavity up to the superior parts of the turbinates is covered with olfactory epithelium. In humans the olfactory region comprises up to $10 \%$ of the surface area of the nasal epithelium while accounting for about $30 \%$ of the surface area in rodents ${ }^{38}$. The olfactory epithelium is formed by columnar epithelial cells, olfactory neurons, supporting cells, basal cells and Bowman's glands ${ }^{\mathbf{4 1}}$. Olfactory neurons are the only neurons having their cell bodies located in a distal epithelium and their nonmotile cilia processes extend into the mucus hence being in direct contact to the environment (Figure 3). Turbulences at the olfactory cleft increase the residence time of the inspired air to increase the interaction of the olfactory receptors with odorants. Hence, small number of odorant substances can be detected ${ }^{41}$. The unmyelinated axons of olfactory neurons spread through the basal lamina and form the fila olfactoria nerve bundles enclosed by olfactory ensheathing cells and olfactory nerve fibroblasts ${ }^{48}$. The ensheathed nerve bundles travel through the cribriform plate of the ethmoid bone into the CNS and terminate at the olfactory bulb that project directly to the piriform cortex, amygdala, entorhinal cortex and olfactory nuclei 49. Compared to the respiratory epithelium the olfactory region is less perfused, but still well vasculated. The serous mucus produced by the Bowman'sglands is not well characterized in the literature. The lamina propria underneath the olfactory epithelium harbours blood and lymphatic vessels in addition to immune cells connected to the deep cervical lymph.

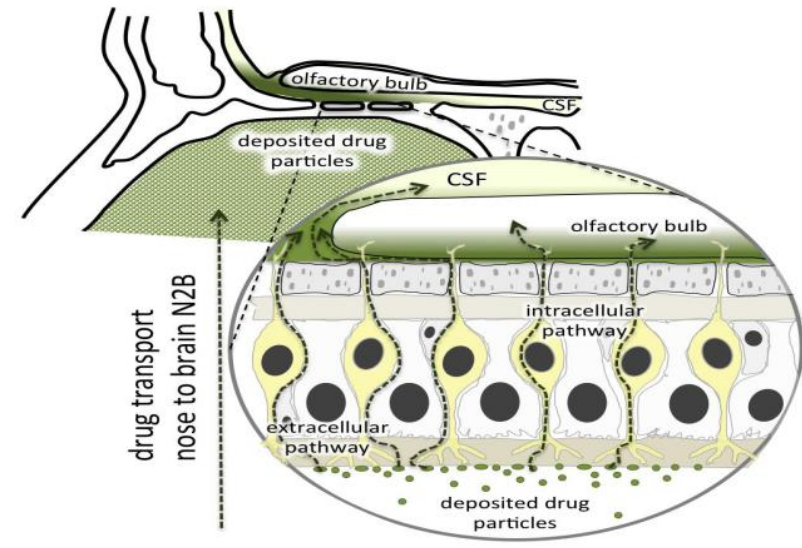

Figure 3: Postulated N2B transport mechanism: dispersed drug particles (coloured in green) are inspired with the aid of a nasal pump spray or an aerosol generator. Drug molecules depositing at the olfactory region diffuse through extracellular pathways (green arrows) to the CSF (see left side) or being transported via intracellular pathways to the olfactory bulb (see right side) and from here to other parts of the $\mathrm{CNS}^{47}$.

\section{ABSORPTION AND TRANSPORT MECHANISM OF THE N2B ROUTE}

Numerous studies have demonstrated central effects of N2B delivered drugs in rodents, most of these studies did not show pharmacokinetic (PK) data or evidence for brain uptake. Hence, the PK and transport mechanism is still far from being elucidated. It appears that intranasal delivery is a combination of different pathways ${ }^{\mathbf{4 0}}$. It was found that crossing of the epithelial barrier can include intracellular or extracellular pathways. Intracellular pathways across the olfactory epithelium include endocytosis into olfactory neurons shown for several viruses and some proteins like peroxidase or albumin $\mathbf{5 0 , 5 1}$ or transcytosis across supporting cells to the lamina propria. In addition, the intracellular uptake by endocytosis and transcytosis across the respiratory epithelium into trigeminal nerve processes or basal lamina, respectively, has been observed $\mathbf{5 2 , 5 3}$. Paracellular diffusion through epithelial tight junctions to the underlying basal lamina is the dominant extracellular transport pathways across either the olfactory or respiratory epithelia (Figure 2) ${ }^{40}$. The permeability of the nasal epithelium is comparable to the intestinal epithelium ${ }^{\mathbf{5 4}}$. The use of absorption enhancers like the natural polymer chitosan or lipophilic additives can increase the paracellular passage ${ }^{\mathbf{5 5}}$.

After uptake to or through the epithelium, different transport pathways have been implicated. N2B delivery of radioactive labelled IGF-1 and interferon in rodents and monkeys seemed to occur along trigeminal and olfactory nerves and to reach first the brainstem and olfactory bulb before the proteins are distributed over the CNS ${ }^{\mathbf{5 6 , 5 7}}$. Molecules being taken-up via intracellular pathways continue their passage via anterograde axonal transport. Peroxidase is likely to be purely transported with axonal transport and kinetic studies match very well with mathematical predictions taking into account the transport rate ${ }^{\mathbf{4 0}}$. Drugs that have been taken-up by transcellular diffusion and convection can be absorbed by the lymphatic or vascular system (and thereby having 
a low probability of entering the brain) or diffuse to perineural or perivascular spaces and thereby enter the cranial compartment. The perineural spaces of the olfactory and trigeminal nerves seem to allow transport to the CSF of the subarachnoid space ${ }^{58}$. However, some studies suggest that $\mathrm{N} 2 \mathrm{~B}$ transported substances may be present in the brain without being detectable in the CSF 54. Mathematical predictions, however, strongly suggest that convection/bulk flow along olfactory and trigeminal nerves is the most plausible mechanism ${ }^{\mathbf{4 0}}$.

\section{ADVANTAGES OF NASAL ROUTE}

$>$ It provides Easy accessibility and needle free drug application.

$>$ The drug can be administered without the necessity of trained personnel facilitates (self-medication).

$>$ Improving patient compliance compared to parenteral routes.

$>$ It provides good penetration of, especially lipophilic, low molecular weight drugs through the nasal mucosa.

$>$ It provides rapid absorption and fast onset of action due to a relatively large absorptive surface and high vascularization.

$>$ Nasal administration of suitable drugs would therefore be effective in emergency therapy as alternative to parenteral administration routes.

$>$ It avoids the hepatic first-pass metabolism and thus potential for dose reduction compared to oral delivery.

> Potential for direct delivery of drugs to the central nervous system via the olfactory region under bypassing the blood-brain-barrier.

> Direct delivery of vaccine to lymphatic tissue and secretory immune response at distant mucosal sites.

\section{DISADVANTAGES OF NASAL ROUTE}

$>$ Residence time of drug reduces due to the mucociliary clearance.

$>$ It is not applicable to all drugs.

$>$ Due to the lack of adequate aqueous solubility it shows insufficient absorption.

$>$ Depending on aqueous solubility of drug it requires high volume of dose $(25-200 \mathrm{ml})$.

$>$ Some drugs can cause nasal irritation.

$>$ Some drugs may undergo metabolic degradation in the nasal cavity.

$>$ It is less suitable for chronically administered drugs.

$>$ Those drugs which require sustained blood levels should not be considered for nasal delivery as there is no conventional way of formulating sustained release type nasal dosage forms.

\section{LIMITATIONS OF INTRANASAL DRUG DELIVERY}

> The absorption enhancers used to improve nasal drug delivery system may have histological toxicity which is not yet clearly established.

$>$ Absorption surface area is less when compared to GIT.

$>$ Once the drug administered cannot be removed.

\section{REASON FOR DEVELOPMENT OF NASAL DELIVERY}

Nasal drug delivery is a useful delivery method for drugs that are active in low doses and show minimal or no oral bioavailability. The nasal route circumvents hepatic first pass elimination associated with the oral delivery; it is easily accessible and suitable for selfmedication. Currently, two classes of nasally delivered therapeutic agents are on the market. The first one comprises low molecular weight and hydrophobic drugs for the treatment of the nasal mucosa and sinus, including decongestants, topical steroids, antibiotics and other (OTC) products. The second class encompasses a few drugs, which have sufficient nasal absorption for displaying systemic effects. Important candidates are the compounds, generally administered by injection and hardly absorbed after oral administration, due to their instability in the gastrointestinal tract, poor absorption properties, and their rapid and extensive biotransformation $^{59}$.

\section{INTRANASAL DRUG DELIVERY FOR ALZHEIMER'S DISEASE TREATMENT}

Intranasal (i.n.) delivery has come to the forefront as an alternative to invasive delivery methods. Nasal administration of pharmacologically active molecules, first developed by Frey in 1991, enables their potential absorption to the CNS bypassing the limitations of the blood--brain barrier (BBB) because of the unique connections that the olfactory and trigeminal nerves provide between the brain and external environment ${ }^{\mathbf{6 0}}$. Possible mechanisms of transport of active molecules may involve a combination of axonal transport from the olfactory neurons of the olfactory epithelium to the olfactory bulb, and of extracellular transport routes involving bulk flow and diffusion within perineuronal channels and perivascular spaces or lymphatic channels directly connected to the cerebrospinal fluid (CSF) ${ }^{\mathbf{6 1 , 6 2}}$. Advantages of i.n. administration include targeting of therapeutics to the CNS with rapid achievement of drug levels in the target tissue, and less systemic exposure and fewer side effects with avoidance of first-pass metabolism ${ }^{\mathbf{6 3 , 6 4}}$ For a therapeutic to be absorbed and become bioavailable in the CNS after intranasal administration, the drug molecule has to go through the mucus layer and cross the epithelial membrane of the nasal cavity, thus bypassing the clearance mechanisms imposed by the mucociliary apparatus, the broad range of metabolic enzymes present in the nasal tissues, and the efflux transporters that reside in the apical area of ciliated epithelial cells and in the submucosal vessels of the human olfactory region ${ }^{\mathbf{6 5 , 6 6}}$. Thus, physiological conditions, physicochemical properties of drugs and formulations, and the deposition methodologies of the formulations represent key factors when the aim is the development of a successful nasal medicine.

\section{Galantamine}

Due to low solubility $(35 \mathrm{mg} / \mathrm{ml})$ and dose volume limitations $(100 \mu \mathrm{l})$, the commercially available hydrobromide salt of galantamine is not suitable for i.n. dosing ${ }^{\mathbf{6 7 , 6 8}}$. The typical oral dose for galantamine is 8 
$\mathrm{mg}$ and therefore it is necessary to increase its solubility at least to $80 \mathrm{mg} / \mathrm{ml}$. This goal was brilliantly reached by using a counter ion exchange approach, with which the traditional counter ion bromide was replaced with lactate by using an anion exchange column consisting of Q Sepharose ${ }^{69}$. Lactate was chosen because it favors a strong interaction, through hydrogen bonding, with water owing to its hydroxyl and carbonyl groups. Compared with galantamine hydrobromide, galantamine lactate showed remarkable increased solubility (up to $400 \mathrm{mg} / \mathrm{ml}$ ) and comparable stability and in vitro cellular toxicity. To maximize the bioavailability after i.n. administration, galantamine lactate $(35-80 \mathrm{mg} / \mathrm{ml})$ was formulated with several excipients such as methylb-cyclodextrin $30 \mathrm{mg} / \mathrm{ml}$, didecanoyl- L-aphosphatidylcholine $1.7 \mathrm{mg} / \mathrm{ml}$ and edetate disodium dihydrate $2.0 \mathrm{mg} / \mathrm{ml}^{70}$. The mixture of these three permeation enhancers resulted in a fourfold increase in the in vitro galantamine permeation across the epithelial barrier, high cell viability and low cytotoxicity. This formulation was also tested in a rat pharmacokinetic model, to study the pharmacokinetic profile of the oral versus i.n. administration. The i.n. galantamine had a shortened Tmax relative to the oral formulation ( $5 \mathrm{~min}$ versus $240 \mathrm{~min}$, respectively) and nearly fourfold increase in $\mathrm{Cmax}(12,100 \pm 8000 \mathrm{ng} / \mathrm{ml}$ versus $3200 \pm$ $200 \mathrm{ng} / \mathrm{ml}$ ). Finally, the hypothesis of reduced GIrelated side effects for i.n. versus oral dosing was tested with a ferret model ${ }^{71,72}$. Clearly, a significant decrease in GI-related side effects was observed when galantamine was administered by the i.n. route. In particular, during the first $4 \mathrm{~h}$ after i.n. administration only three emesis and retching events were observed, whereas 34 events were recorded within $4 \mathrm{~h}$ after oral administration. Despite the promising results, so far the formulation has not been tested in $\mathrm{AD}$ patients.

\section{Physostigmine}

The physostigmine analogue (3aS)-cis-1,2,3,3a,8,8ahexahydro- 1,3a,8-trimethyl-pyrrolo-[2,3b]-indol-5-yl3,4-dihydro- 2-isoquinolincarboxylate (NXX-066), which acts as an ChEI and showed potential for treating $\mathrm{AD}$, is well absorbed from the GI tract, but its oral bioavailability is poor to moderate in rats and dogs because of presystemic metabolism ${ }^{73}$. The aims of the study conducted by Dahlin and BjÖrk were, thus, to investigate the systemic absorption of nasally administered NXX-066 in rats and to compare the uptake of the drug into the CSF after nasal or intravenous administration ${ }^{74}$. Nasal administration of NXX-066 resulted in extremely rapid and complete absorption into the systemic circulation followed by a rapid decline of the plasma concentrations. The intravenous and nasal concentration--time profiles of NXX-066 were similar, with the mean values of each pharmacokinetic parameter not differing significantly between the two administration routes. The data collected allowed speculation that, as the oral bioavailability is poor to moderate owing to presystemic metabolism, nasal delivery could be a good alternative to the parenteral route for NXX-066 administration.

\section{Rivastigmine}

For i.n. administration, rivastigmine was formulated in conventional multilamellar liposomes obtained by the wellknown lipid layer hydration method and using cholesterol and soy lecithin as lipid components ${ }^{74}$. The in vitro release studies showed that there was an initial burst release followed by a lag phase. The in vivo studies showed that intranasally administered liposomes significantly increased the exposure and resulted in a higher concentration in rat brain. As a matter of fact, the AUC $(36.13 \pm 1.87 \mathrm{mg} \mathrm{min} / \mathrm{ml})$ was fivefold higher than orally administered free drug $(6.58 \pm 0.26 \mathrm{mg} \mathrm{min} / \mathrm{ml})$ and almost threefold higher than free drug administrated intranasally $(12.99 \pm 0.87 \mathrm{mg} \mathrm{min} / \mathrm{ml})$. If approved for human use, this sustained release of rivastigmine from liposomes may be used to reduce the frequency of administration.

\section{Tacrine}

To assess the efficiency of i.n. administration, a tacrine solution in propylene glycol was prepared and drug concentrations in mice blood and brain were determined 75. The study showed that following intranasal administration, tacrine reached the rabbit brain quickly $\left(\mathrm{T}_{\max } 60 \mathrm{~min}\right)$ compared with intravenous administration $\left(\mathrm{T}_{\max } 120 \mathrm{~min}\right.$ ), suggesting a direct transport into the brain from the nasal cavity. This selective localization of tacrine in the brain may be helpful in reducing dose, frequency of dosing and dose-dependent side effects. Starting from these data and in order to increase brain bioavailability, a mucoadhesive microemulsion of tacrine was prepared and characterized. The mentioned microemulsion formulation contained a mucoadhesive substance, which favored adhesion to the mucous membranes lining the nasal mucosa and improved drug targeting to the CNS ${ }^{76}$. The results demonstrated rapid and larger extent of transport of tacrine into the mice brain and fastest regain of memory loss in scopolamineinduced amnesic mice after intranasal administration of tacrine microemulsion.

\section{7ß-Estradiol}

To overcome the low estradiol water solubility $(0.008$ $\mathrm{mg} / \mathrm{ml}$ ), making feasible the nasal administration of an effective dose (i.e., $0.1 \mathrm{mg}$ in a volume of $0.1 \mathrm{ml}$ ), four water-soluble prodrugs have been proposed. They are three phenolic esters, 3-N,N-dimethylamino butyl ester hydrochloride, 3-N,N-diethylamino propionyl ester hydrochloride and 3-N, N,N-trimethylamino butyl ester iodide, and one alcoholic ester, 17-N,N-dimethylamino butyl ester hydrochloride. All of these were significantly more soluble than $17 \beta$-estradiol, but only the alcoholic prodrug was found to be chemically stable. Moreover, the rat CSF concentration of estradiol following nasal administration of this compound was higher than that following intravenous administration. These preclinical data suggest that the drug can reach the CSF via a direct pathway through the nasal cavity and that the nasal spray solution is the best formulation for this ester.

Another preclinical attempt to improve the estradiol solubility was encapsulation in chitosan nanoparticles (final concentration $2 \mathrm{mg} / \mathrm{ml}$ ) ${ }^{77}$. Microdialysis studies showed that estradiol levels in rat CSF administered 
with estradiol by means of the nasal route $\left(\mathrm{C}_{\max } 76.4 \pm\right.$ $14.0 \mathrm{ng} / \mathrm{ml}$ and AUC $12788.4 \pm 4093.6 \mathrm{ng} \mathrm{min} / \mathrm{ml}$ ) were significantly higher than those obtained after i.v. injection, despite the much lower estradiol concentrations in rat plasma after nasal route administration with respect to those measured after i.v. injection. It has been seen that chitosan behaves as a bioadhesive material and binds strongly to the negatively charged mucin through electrostatic interactions, thus increasing significantly the half-time of clearance of estradiol.

Table 1: Intranasal drugs delivery for treatment of Alzheimer's disease

\begin{tabular}{|l|l|l|l|l|}
\hline S.No. & Drug & Dosage & Studies & Ref. \\
\hline $\mathbf{1}$ & Galantamine lactate & $35-80 \mathrm{mg} / \mathrm{ml}$ & Preclinical & 66,67 \\
\hline $\mathbf{2}$ & Physostigmine analogue (NXX-006) & $6.4 \mathrm{mg} / \mathrm{ml}$ & Preclinical & 71 \\
\hline $\mathbf{3}$ & Rivastigmine & - & Preclinical & 72 \\
\hline $\mathbf{4}$ & Tacrine microemulsion & - & Preclinical & 73 \\
\hline $\mathbf{5}$ & Estradiol & $0.1 \mathrm{mg} / \mathrm{kg}$ & Preclinical & 75 \\
& & $2 \mathrm{mg} / \mathrm{ml}$ & & \\
\hline
\end{tabular}

\section{CONCLUSION}

Traditionally mainly the marketed nasal products are used for the management of local diseases in the upper respiratory tract such as nasal allergy (e.g. allergic rhinitis), nasal infections and nasal congestion, the nasal route of delivery is also increasingly exploited for systemic delivery of low molecular weight drugs, peptide and proteins and for vaccines

The terms direct nose to brain delivery (Intranasal delivery) of drugs; this is evidently a very exciting area of research and development due to the potential of treating neurodegenerative diseases (e.g. Alzheimer's) more efficiently. However, it is also evident that in order to obtain sufficient therapeutic drug levels in the brain it

\section{REFERENCES}

1. Reese TS, Karnovsky MJ. Fine structural localization of a blood-brain barrier to exogenous peroxidase. The Journal of cell biology. 1967, 34(1), 207-217.

2. Crone $\mathrm{C}$, Olesen SP. Electrical resistance of brain microvascular endothelium. Brain research. 1982, 241(1), 4955 .

3. Butt AM, Jones HC, Abbott NJ. Electrical resistance across the blood-brain barrier in anaesthetized rats: a developmental study. The Journal of physiology. 1990, 429, 47.

4. Banks WA. Characteristics of compounds that cross the bloodbrain barrier. BMC neurology. 2009, 9(1), 1.

5. Dick AP, Harik SI, Klip A, Walker DM. Identification and characterization of the glucose transporter of the blood-brain barrier by cytochalasin B binding and immunological reactivity. Proceedings of the National Academy of Sciences. 1984, 81(22), 7233-7.

6. Jefferies WA, Brandon MR, Hunt SV, Williams AF, Gatter $\mathrm{KC}$, Mason DY. Transferrin receptor on endothelium of brain capillaries.

7. Banks WA. The blood-brain barrier: connecting the gut and the brain. Regulatory peptides. 2008, 149(1), 11-4.

8. Miller DS. Regulation of P-glycoprotein and other ABC drug transporters at the blood-brain barrier. Trends in pharmacological sciences. 2010, 31(6), 246-54.

9. Wang B. Drug transporters: molecular characterization and role in drug disposition. You G, Morris ME, editors. John Wiley \& Sons; 2007.

10. Neuwelt E, Abbott NJ, Abrey L, Banks WA, Blakley B, Davis T, Engelhardt B, Grammas P, Nedergaard M, Nutt J, Pardridge W. Strategies to advance translational research into brain barriers. The Lancet Neurology. 2008, 7(1), 84-96. will be necessary to develop novel delivery system that will be capable to efficiently enhance the transport the drug from the nasal cavity to the brain. So far, in general for simple drug solutions not more than $1 \%$ of the drug will be reaching into the brain.

In review, the advantages of intranasal delivery are significant. It is equally rapid and non-invasive. It cross the $\mathrm{BBB}$ and target the CNS, reducing systemic exposure and thus systemic side effects. Even for drugs that can cross the BBB, it can reduce systemic side effects by reducing the need for the drug to come into the systemic circulation. It does not require any alteration of the therapeutic agent being delivered and should work for a broad range of drugs.

11. American Psychiatric Association, American Psychiatric Association. Diagnostic and statistical manual of mental disorders (DSM). Washington, DC: American psychiatric association. 1994, 143-7.

12. Viswanathan A, Rocca WA, Tzourio C. Vascular risk factors and dementia How to move forward?. Neurology. 2009, 72(4), 368-74.

13. Jellinger KA. The enigma of mixed dementia. Alzheimers Dement 2007, 3, 40-53.

14. Clarfield AM. The decreasing prevalence of reversible dementias: an updated meta-analysis. Archives of internal medicine. 2003, 163(18), 2219-29.

15. Katzman R. The prevalence and malignancy of Alzheimer disease: a major killer. Archives of neurology. 1976, 33(4), 217-8.

16. Sperling RA, Aisen PS, Beckett LA, Bennett DA, Craft S, Fagan AM, Iwatsubo T, Jack CR, Kaye J, Montine TJ, Park DC. Toward defining the preclinical stages of Alzheimer's disease: Recommendations from the National Institute on Aging-Alzheimer's Association workgroups on diagnostic guidelines for Alzheimer's disease. Alzheimer's \& dementia. 2011, 7(3), 280-92.

17. Jack CR, Albert MS, Knopman DS, McKhann GM, Sperling $\mathrm{RA}$, Carrillo MC, Thies B, Phelps $\mathrm{CH}$. Introduction to the recommendations from the National Institute on AgingAlzheimer's Association workgroups on diagnostic guidelines for Alzheimer's disease. Alzheimer's \& Dementia. 2011, 7(3), 257-62.

18. McKhann G, Drachman D, Folstein M, Katzman R, Price D, Stadlan EM. Clinical diagnosis of Alzheimer's disease Report of the NINCDS-ADRDA Work Group* under the auspices of Department of Health and Human Services Task Force on Alzheimer's Disease. Neurology. 1984, 34(7), 939-. 
19. Kurz A, Perneczky R. Novel insights for the treatment of Alzheimer's disease. Progress in Neuro-Psychopharmacology and Biological Psychiatry. 2011, 35(2), 373-9.

20. Kumar A, Dogra S. Neuropathology and therapeutic management of Alzhei- 640 mer's disease - an update. Drugs Future 2008, 33(5), 433-46.

21. Hardy J. The amyloid hypothesis for Alzheimer's disease: a critical reappraisal. Journal of neurochemistry. 2009, 110(4), 1129-34.

22. Anand R, Gill KD, Mahdi AA. Therapeutics of Alzheimer's disease: Past, present and future. Neuropharmacology. 2014, 76, 27-50.

23. Dal Prà I, Chiarini A, Gui L, Chakravarthy B, Pacchiana R, Gardenal E, Whitfield JF, Armato U. Do Astrocytes Collaborate with Neurons in Spreading the "Infectious" A $\beta$ and Tau Drivers of Alzheimer's Disease?. The Neuroscientist. 2015, 21(1), 9-29.

24. Galimberti D, Ghezzi L, Scarpini E. Immunotherapy against amyloid pathology in Alzheimer's disease. Journal of the neurological sciences. 2013, 333(1), 50-4.

25. Salomone S, Caraci F, Leggio GM, Fedotova J, Drago F. New pharmacological strategies for treatment of Alzheimer's disease: focus on disease modifying drugs. British journal of clinical pharmacology. 2012, 73(4), 504-17.

26. Rosenmann H. Immunotherapy for targeting tau pathology in Alzheimer's disease and tauopathies. Current Alzheimer Research. 2013, 10(3), 217-28.

27. Antanitus DS. A theory of cortical neuron-astrocyte interaction. The Neuroscientist. 1998, 4(3), 154-9.

28. Roth AD, Ramírez G, Alarcón R, Von Bernhardi R. Oligodendrocytes damage in Alzheimer's disease: beta amyloid toxicity and inflammation. Biological research. 2005 , 38(4), 381-7.

29. Subasinghe S, Unabia S, Barrow CJ, Mok SS, Aguilar MI, Small DH. Cholesterol is necessary both for the toxic effect of $\mathrm{A} \beta$ peptides on vascular smooth muscle cells and for $\mathrm{A} \beta$ binding to vascular smooth muscle cell membranes. Journal of neurochemistry. 2003, 84(3), 471-9.

30. Xu Y, Yan J, Zhou P, Li J, Gao H, Xia Y, Wang Q. Neurotransmitter receptors and cognitive dysfunction in Alzheimer's disease and Parkinson's disease. Progress in neurobiology. 2012, 97(1), 1-3.

31. Armato U, Chakravarthy B, Pacchiana R, Whitfield JF. Alzheimer's disease: An update of the roles of receptors, astrocytes and primary cilia (Review). International journal of molecular medicine. 2013, 31(1), 3-10.

32. Yasojima K, McGeer EG, McGeer PL. Relationship between beta amyloid peptide generating molecules and neprilysin in Alzheimer disease and normal brain. Brain research. 2001, 919(1), 115-21.

33. Braak H, Del Tredici K. Alzheimer's pathogenesis: is there neuron-to-neuron propagation?. Acta neuropathologica. 2011, 121(5), 589-95.

34. Tuppo EE, Arias HR. The role of inflammation in Alzheimer's disease. Int J Biochem Cell Biol 2005, 37(2), 289-305.

35. Eisele YS, Obermüller U, Heilbronner G, Baumann F, Kaeser SA, Wolburg H, Walker LC, Staufenbiel M, Heikenwalder M, Jucker M. Peripherally applied A $\beta$-containing inoculates induce cerebral $\beta$-amyloidosis. Science. 2010, 330(6006), 9802.

36. Talantova M, Sanz-Blasco S, Zhang X, Xia P, Akhtar MW, Okamoto SI, Dziewczapolski G, Nakamura T, Cao G, Pratt AE, Kang YJ. A $\beta$ induces astrocytic glutamate release, extrasynaptic NMDA receptor activation, and synaptic loss. Proceedings of the National Academy of Sciences. 2013, 110(27), E2518-27.

37. Lochhead JJ, Thorne RG. Intranasal delivery of biologics to the central nervous system. Advanced drug delivery reviews. 2012, 64(7), 614-28

38. Doty RL. Handbook of olfaction and gustation. John Wiley \& Sons; 2015, 11.

39. Kumar A, Singh A, Ekavali, A review on Alzheimer's disease pathophysiology and its management: an update,
Pharmacological Reports 67; (2015):195-203 http://dx.doi.org/10.1016/j.pharep.2014.09.004

40. Kiyono H, Fukuyama S. NALT-versus Peyer's-patch-mediated mucosal immunity. Nature Reviews Immunology. 2004, 4(9), 699-710.

41. Harkema JR, Carey SA, Wagner JG. The nose revisited: a brief review of the comparative structure, function, and toxicologic pathology of the nasal epithelium. Toxicologic pathology. 2006, 34(3), 252-69.

42. Finger TE, Jeor VL, Kinnamon JC, Silver WL. Ultrastructure of substance P-and CGRP-immunoreactive nerve fibers in the nasal epithelium of rodents. Journal of Comparative Neurology. 1990, 294(2), 293-305.

43. Bojsen-Møller F. Demonstration of terminalis, olfactory, trigeminal and perivascular nerves in the rat nasal septum. Journal of Comparative Neurology. 1975, 159(2), 245-56.

44. Costantino HR, Illum L, Brandt G, Johnson PH, Quay SC. Intranasal delivery: physicochemical and therapeutic aspects. International journal of pharmaceutics. 2007, 337(1), 1-24.

45. Field PM, Li Y, Raisman G. Ensheathment of the olfactory nerves in the adult rat. Journal of neurocytology. 2003, 32(3), 317-24.

46. Carmichael ST, Price JL. Limbic connections of the orbital and medial prefrontal cortex in macaque monkeys. Journal of Comparative Neurology. 1995, 363(4), 615-41.

47. Stützle Martina, Flamm Johannes, Carle Stefan, Schindowski Katharina, Nose-to-Brain delivery of insulin for Alzheimer's disease, ADMET \& DMPK. 2015; 3(3):190-202; doi: 10.5599/admet.3.3.184

48. Thorne RG, Emory CR, Ala TA, Frey WH. Quantitative analysis of the olfactory pathway for drug delivery to the brain. Brain research. 1995, 692(1), 278-82.

49. Kristensson K. Microbes' roadmap to neurons. Nature Reviews Neuroscience. 2011, 12(6), 345-57.

50. Anton F, Peppel P. Central projections of trigeminal primary afferents innervating the nasal mucosa: a horseradish peroxidase study in the rat. Neuroscience. 1991, 41(2-3), 617 28.

51. Deatly AM, Haase AT, Fewster PH, Lewis E, Ball MJ. Human herpes virus infections and Alzheimer's disease. Neuropathology and applied neurobiology. 1990, 16(3), 21323.

52. Hosoya KI, Kubo H, Natsume H, Sugibayashi K, Morimoto Y, Yamashita S. The structural barrier of absorptive mucosae: Site difference of the permeability of fluorescein isothiocyanate-labelled dextran in rabbits. Biopharmaceutics \& drug disposition. 1993, 14(8), 685-95.

53. Davis SS, Illum L. Absorption enhancers for nasal drug delivery. Clinical pharmacokinetics. 2003, 42(13), 1107-28.

54. Thorne RG, Pronk GJ, Padmanabhan V, Frey W2. Delivery of insulin-like growth factor-I to the rat brain and spinal cord along olfactory and trigeminal pathways following intranasal administration. Neuroscience. 2004, 127(2), 481-96.

55. Thorne RG, Hanson LR, Ross TM, Tung D, Frey WH. Delivery of interferon- $\beta$ to the monkey nervous system following intranasal administration. Neuroscience. 2008, 152(3), 785-97

56. Johnston M, Zakharov A, Papaiconomou C, Salmasi G, Armstrong D. Evidence of connections between cerebrospinal fluid and nasal lymphatic vessels in humans, non-human primates and other mammalian species. Cerebrospinal fluid research. 2004, 1(1), 1 .

57. Kushwaha SK, Keshari RK, Rai AK. Short Communication: Advances in nasal trans-mucosal drug delivery. Journal of applied pharmaceutical science. 2011, 1(7), 21.

58. Frey WH. Neurologic agents for nasal administration to the brain. World Intellectual Property Organization. 1991, 5, 89.

59. Illum L. Transport of drugs from the nasal cavity to the central nervous system. European Journal of Pharmaceutical Sciences. 2000, 11(1), 1-8.

60. Kumar TA, David GF, Sankaranarayanan A, Puri V, Sundram KR. Pharmacokinetics of progesterone after its administration to ovariectomized rhesus monkeys by injection, infusion, or 
nasal spraying. Proceedings of the National Academy of Sciences. 1982, 79(13), 4185-9.

61. Wang Y, Aun R, Tse FL. Brain uptake of dihydroergotamine after intravenous and nasal administration in the rat. Biopharmaceutics \& drug disposition. 1998, 19(9), 571-5.

62. Wang D, Gao Y, Yun L. Study on brain targeting of raltitrexed following intranasal administration in rats. Cancer chemotherapy and pharmacology. 2006, 57(1), 97-104.

63. Marttin E, Schipper NG, Verhoef JC, Merkus FW. Nasal mucociliary clearance as a factor in nasal drug delivery. Advanced drug delivery reviews. 1998, 29(1), 13-38.

64. Dhuria SV, Hanson LR, Frey WH. Intranasal delivery to the central nervous system: mechanisms and experimental considerations. Journal of pharmaceutical sciences. 2010, 99(4), 1654-73.

65. Chauhan MB, Chauhan NB. Brain Uptake of Neurotherapeutics after Intranasal versus Intraperitoneal Delivery in Mice. Journal of neurology and neurosurgery. 2015, 2(1).

66. Agoston S. New Neuromuscular Blocking Agents: Basic and Applied Aspects. Kharkevich DA, editor. Springer Science \& Business Media; 2012.

67. Leonard AK, Sileno AP, MacEvilly C, Foerder CA, Quay SC, Costantino HR. Development of a novel high-concentration galantamine formulation suitable for intranasal delivery. Journal of pharmaceutical sciences. 2005, 94(8), 1736-46.

68. Leonard AK, Sileno AP, Brandt GC, Foerder CA, Quay SC, Costantino HR. In vitro formulation optimization of intranasal galantamine leading to enhanced bioavailability and reduced emetic response in vivo. International journal of pharmaceutics. 2007, 335(1), 138-46.

69. Yamashita M, Yamashita M, Tanaka J, Chagi K, Takeda S, Kurihara T, Takeda Y, Fujii Y. Vomiting induction by ipecac syrup in $\operatorname{dog} s$ and ferrets. The Journal of toxicological sciences. 1997, 22(5), 409-12.

70. Hasegawa M, Sasaki T, Sadakane K, Tabuchi M, Takeda Y, Kimura M, Fujii Y. Studies for the emetic mechanisms of ipecac syrup (TJN-119) and its active components in ferrets: involvement of 5-hydroxytryptamine receptors. The Japanese Journal of Pharmacology. 2002, 89(2), 113-9.

71. Snape MF, Misra A, Murray TK, et al. A comparative study in rats of the in vitro and in vivo pharmacology of the acetylcholinesterase inhibitors Tacrine, Donepezil and NXX066. Neuropharmacology 1999, 38, 181-93

72. Dahlin M, Björk E. Nasal administration of a physostigmine analogue (NXX-066) for Alzheimer's disease to rats. International journal of pharmaceutics. 2001, 212(2), 267-74.

73. Arumugam K, Subramanian G, Mallayasamy S, Averineni R, Reddy M, Udupa N. A study of rivastigmine liposomes for delivery into the brain through intranasal route. Acta pharmaceutica. 2008, 58(3), 287-97.

74. Jogani VV, Shah PJ, Misra AR, Mishra P, Mishra AK. Nose-to-brain delivery of tacrine. Journal of pharmacy and pharmacology. 2007, 59(9), 1199-205.

75. Jogani VV, Shah PJ, Mishra P, Mishra AK, Misra AR. Intranasal mucoadhesive microemulsion of tacrine to improve brain targeting. Alzheimer Disease \& Associated Disorders. 2008, 22(2), 116-24.

76. Al-Ghananeem AM, Traboulsi AA, Dittert LW, Hussain AA. Targeted brain delivery of $17 \beta$-estradiol via nasally administered water soluble prodrugs. AAPS PharmSciTech. 2002, 3(1), 40-7.

77. Wang X, Chi N, Tang X. Preparation of estradiol chitosan nanoparticles for improving nasal absorption and brain targeting. European Journal of Pharmaceutics and Biopharmaceutics. 2008, 70(3), 735-40. 